\title{
A questão da autocensura projetual em estudantes de arquitetura e as impressoras tridimensionais de baixo custo
}

\author{
The Problem of self-censorship in architectural students and the low cost tree-dimensional printers
}

\author{
- Renan do Nascimento Balzani \\ UnB, Universidade de Brasília. Brazil \\ renan.balzani@gmail.com \\ - Neander Furtado Silva \\ UnB, Universidade de Brasília. Brazil \\ neander.furtado@gmail.com
}

\begin{abstract}
Self-censorship can be observed in architectural students. Due to drawing and development methods of design representation, some students do not create the design they dream about. Believing that you do not have the ability or the technique to represent the ideas on paper or using physical models can cause the self-censorship in the students. The production of physical models is very important for the design thinking and for architectural student's experience. The tree-dimensional printers can help as a tool to print complex volumetric models or detailed models allowing students to create freely.
\end{abstract}

Keywords: Rapid Prototyping, 3D Printing, Design Theory, Architecture, Self-censorship

\section{Introdução}

Neste artigo consideramos que todos os elementos utilizados para transmitir ideias, proposições ou soluções arquitetônicas relacionadas a um espaço que se pretenda construir ou não, constituem representação, sejam eles croquis, maquetes físicas de estudo, desenhos técnicos, modelos virtuais ou maquetes de apresentação.

Embora as ideias de projeto nasçam na mente do arquiteto, as mesmas só podem ser concebidas, compreendidas e desenvolvidas plenamente quando são representadas pelos meios adequados.

Pode-se dizer que diferentes tipos de representação possibilitam diferentes resultados. A cada tipo de representação corresponde um conjunto de ferramentas que o viabiliza. O que é possível produzir com um certo conjunto de ferramentas é, em várias situações, inviável através de outro. Por exemplo não é possível produzir uma pintura com instrumentos de escultura. Partindo da mesma lógica, não seria possível produzir uma escultura com instrumentos de pintura. Em suma, a escolha das ferramentas é muito relevante quando se busca diferentes possibilidades.

Novas tecnologias de representação de projeto surgem e se desenvolvem atualmente. Porém, para que essas técnicas sejam de fato incorporadas à prática projetual e à teoria do projeto, é indispensável a realização de novas pesquisas e estudos que as contemplem.
Nos primeiros estágios do ensino de arquitetura já devem ser introduzidas noções da necessidade de representar o projeto de forma adequada. $\mathrm{O}$ arquiteto Paulo Mendes da Rocha, em seu livro Maquetes de Papel, evidencia a necessidade de produzir maquetes para compreender e analisar o que está sendo projetado. (ROCHA, P. M., 2007. p.11)

Partindo dessa concepção, as maquetes físicas se mostram relevantes. A maquete de estudo cabe ser utilizada não só por estudantes de arquitetura como por profissionais formados. Os modelos ajudam a incorporar amplamente o que está sendo esperado para a execução do projeto, além de mostrar em uma volumetria palpável proporções, jogos de luz e cenários criados pelo objeto arquitetônico representado.

Para Paulo Mendes da Rocha, a maquete de estudo deve ser feita na solidão, com objetos que estão ao alcance. Deve-se respeitar as dimensões dos elementos estruturaise definir bem a volumetria esperada. Segundo o arquiteto, a observação da forma auxilia a compreensão do projeto e completa os croquis e desenhos de estudo. A maquete deve ser feita na solidão, rapidamente e com proporções adequadas, sendo que não necessariamente precisa ser mostrada para outras pessoas. $\mathrm{Ou}$ seja, a produção do modelo deve ser utilizada para a reflexão e não apenas para representar o projeto já concluído como ferramenta de venda da proposta.

A partir dessa visão, pode-se avaliar a possibilidade do uso de impressoras tridimensionais de baixo custo dentro dos ateliês de projeto arquitetônico. Partindo de croquis de 
estudo ou de desenhos técnicos, e com o uso de modeladores tridimensionais, os alunos podem gerar modelos virtuais volumétricos, que posteriormente servirão de base para a impressão tridimensional dos mesmos.

Com o uso dessas ferramentas, as maquetes podem ser executadas rapidamente, tanto os modelos virtuais quanto as impressões. Outra possibilidade do uso dessa tecnologia é a confecção de detalhes construtivos em diferentes escalas com precisão. Com o mesmo arquivo da maquete volumétrica virtual, os estudantes podem criar elementos mais detalhados em outro arquivo para impressão.

Essa materialização consequente da impressão tridimensional pode, a princípio, aumentar a compreensão do que está sendo projetado, esclarecendo incertezas que o desenho técnico poderia gerar, seja pela dificuldade em observar uma representação bidimensional ou pela falta de conhecimento técnico dos profissionais que executam as obras.

William Mitchell argumenta que há um fator indutor forte entre a utilização de instrumentos de desenho tradicionais (réguas $\mathrm{T}$ e paralelas, esquadros, papéis quadriculados, escalímetros, transferidores, etc.) e o tipo de arquitetura produzida por meio dos mesmos. Estes instrumentos foram, segundo Mitchell, desenvolvidos especificamente para a produção de formas predominantemente euclidianas. Ele argumenta que o mesmo ocorre com as técnicas tradicionais de construção artesanal e mecanizada (serrotes, tijolos, fios de prumo, níveis, etc.): tudoé pensado para produzir ângulos retose linhas paralelas, resultando em paredes quase sempre verticais e em superfícies geralmente planas. Como consequência, os arquitetos tendem a desenhar o que podem construir e a construir o que podem desenhar (Mitchell, 2001, p. 352 - 363). A esta tendência denominamos nesta pesquisa 'autocensura'.

Um exemplo de fator causador de autocensura é a dificuldade de representação de modelos físicos utilizando métodos manuais de produção das maquetes em madeira ou papel. Essas técnicas podem exigir um alto nível de perícia e prática para terem resultados satisfatórios. Portanto, a representação de um projeto com maior complexidade formal utilizando essas técnicas se torna um fator desencorajador para o estudante de arquitetura, podendo ocasionar autocensura projetiva.

Acreditamos que a prototipagem rápida não deve ser ensinada simplesmente como um substituto a produção de maquetes de estudo ou de apresentação em arquitetura. Ela deve ser ensinada principalmente para ilustrar a viabilidade da produção de componentes finais únicos através da fabricação digital na indústria. A utilização de impressoras tridimensionais, fresas controladas por computador e cortadoras laser proporcionam aos alunos uma visão antecipada e em escala reduzida do que já está ocorrendo na indústria de componentes construtivos. Portanto, ela ajuda a demonstrar a viabilidade da customização em massa, ou seja, de como formas complexas podem ser produzidas a custos semelhantes àqueles das formas serializadas. Assim os alunos podem compreender que através destas novas tecnologias removem-se os limites formais do modernismo do início do Século XX.

O projeto deve ser concebido e desenvolvido de forma integral desde o princípio. Isto implica em trabalhar tridimensionalmente, tanto virtualmente - no computador como por meio de protótipos rápidos e modelos feitos à mão.

A implementação de técnicas de representação física de projeto poderia diminuir a questão da autocensura. Para tanto, uma possível solução seria o uso da tecnologia de impressão tridimensional de baixo custo nas faculdades de arquitetura e urbanismo.

Como o professor Kalisperis, define no seu texto CAD in Education: Penn State University, de 1996, os usos de métodos computadorizados devem ser utilizados corretamente para maximizar o entendimento do projeto pelos alunos e envolvidos no processo. (Kalisperis, 1996)

A utilização da impressora não determina as linguagens projetuais, mas evidencia aos alunos a possibilidade de irem além de uma linguagem em série, repetitiva e predominantemente ortogonal.

O funcionamento das impressoras tridimensionais de baixo custo é de fácil apreensão aos estudantes de arquitetura. Alunos que possuem conhecimento na utilização de softwares de modelagem tridimensionais podem criar modelos virtuais e imprimi-los.

\section{Metodologia}

A importância deste trabalho está em verificar a influência de máquinas de fabricação digital no processo de projeto. $O$ seu uso pode evidenciar aos alunos novas formas de execução de edificações usando a indústria como aliada direta na produção de elementos construtivos e na concepção de novas técnicas para a construção civil.

Alunas do sexto semestre em arquitetura e urbanismo da Universidade de Brasília, tiveram a oportunidade de utilizar uma impressora tridimensional de baixo custo para visualizar e representar seus projetos.

Nas figuras 1 e 2 as alunas decidiram imprimir um corte detalhando a estrutura do projeto de edificação e seu envoltório.

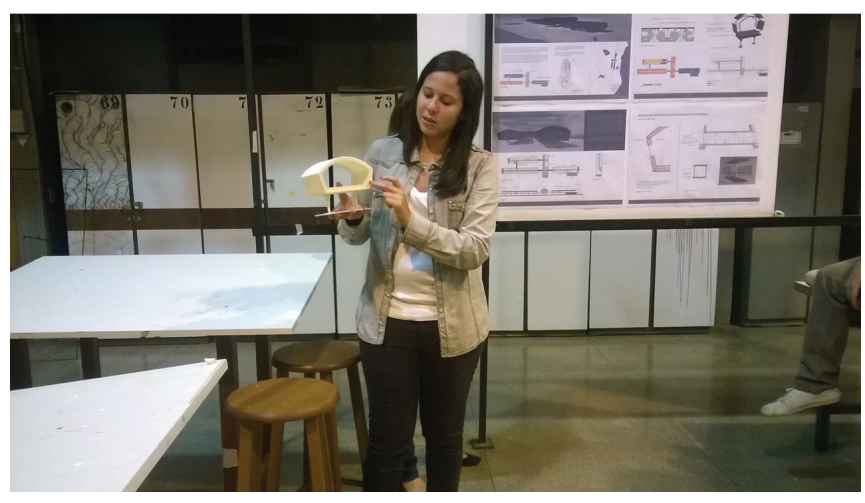

Figura 1: Estudante de arquitetura apresentando seu projeto com o uso de uma maquete impressa. Maquete executada com impressora tridimensional de baixo custo. Projeto: Ana Catarina e Ana Luísa Meira. 


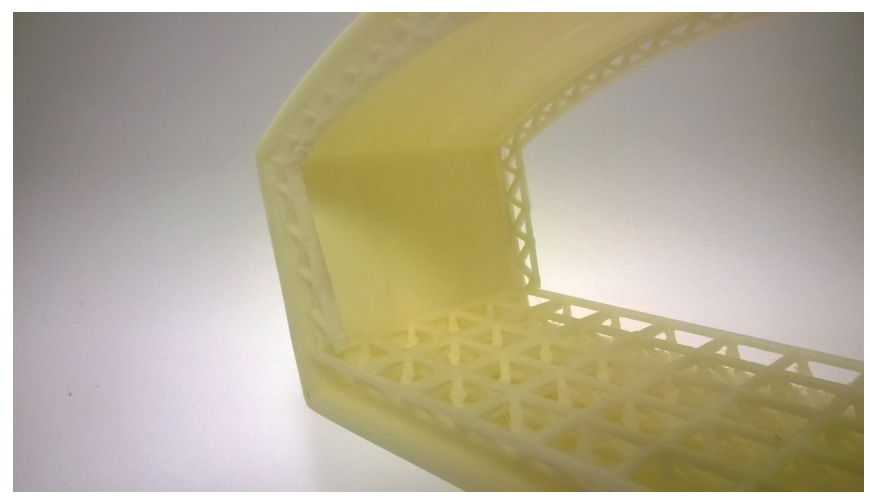

Figura 2: Detalhe estrutural de uma maquete impressa. Maquete executada com impressora tridimensional de baixo custo. Projeto: Ana Catarina e Ana Luísa Meira.

A maquete das figuras 1 e 2 possibilitou a compreensão de um sistema estrutural complexo que dificilmente seria representado através de uma maquete física feita à mão devido ao tempo de curso da disciplina em questão.

O método de investigação consistiu no acompanhamento dos alunos da matéria de Projeto Arquitetônico 02 (PA 02) do curso de graduação em Arquitetura e Urbanismo. Esta disciplina é ministrada no segundo semestre deste curso.

A disciplina enfatiza a prática de projeto de edificações através de representações tridimensionais físicas e virtuais, além da exploração de diferentes linguagens arquitetônicas.

Os aspectos formais das edificações foram salientados, sem, contudo, deixar de analisar os aspectos funcionais, ambientais e construtivos. Foram concebidos e desenvolvidos três projetos, de autoria individual, em grau crescente de dimensões e complexidade. As condicionantes ou restrições formais adotadas deveriam resultar na transição gradual de formas predominantemente ortogonais, passando por composições planares, predominantemente não ortogonais, até alcançar formas predominantemente curvilíneas.

Os modelos foram confeccionados utilizando um modelador de sólidos que possuí a capacidade de criar arquivos em formato.STL (STereoLithography). O programa utilizado para coordenar as impressões foi o Repertier-Host, um software de uso livre. O programa possibilita a visualização previa do modelo e o andamento da impressão.

\section{Resultados}

Três modelos foram escolhidos para serem impressos e analisados. O modelo 01 (figuras 3 e 4) apresenta uma proposta formal mais conservadora, com paredes ortogonais e uma cobertura em formato de onda.

O modelo 02 (figuras 5 e 6) apresenta uma volumetria em forma de arco, compondo a cobertura e com paredes lineares de fechamento lateral.

O modelo 03 (figuras 7 e 8) possui uma geometria não euclidiana. Esses três modelos foram escolhidos por suas formas e soluções arquitetônicas singulares.
O modelo 01 nos permite verificar a possibilidade de os alunos criarem geometrias curvas e representá-las com clareza. O tempo de impressão foi de aproximadamente 3 horas e 23 minutos. Apesar de ter sido impressa, sua forma apresenta uma proposta que poderia ser executada por meios convencionais. No caso do modelo 02 podemos observar a confecção de modelos com geometrias curvas mais precisas. Este modelo também poderia ter sido executado com métodos convencionais. O tempo de impressão foi de aproximadamente 2 horas e 28 minutos.

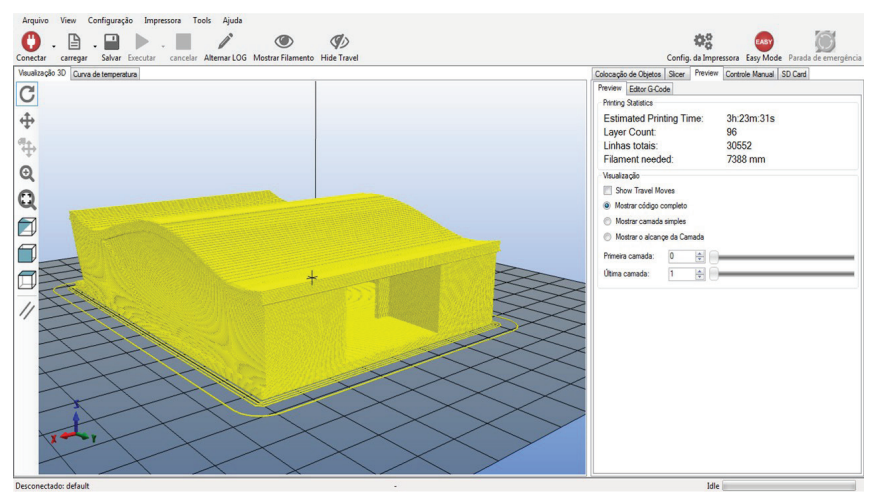

Figura 3: Modelo 01: Maquete de aluno do segundo semestre de arquitetura e urbanismo. Programa Repertier-host.

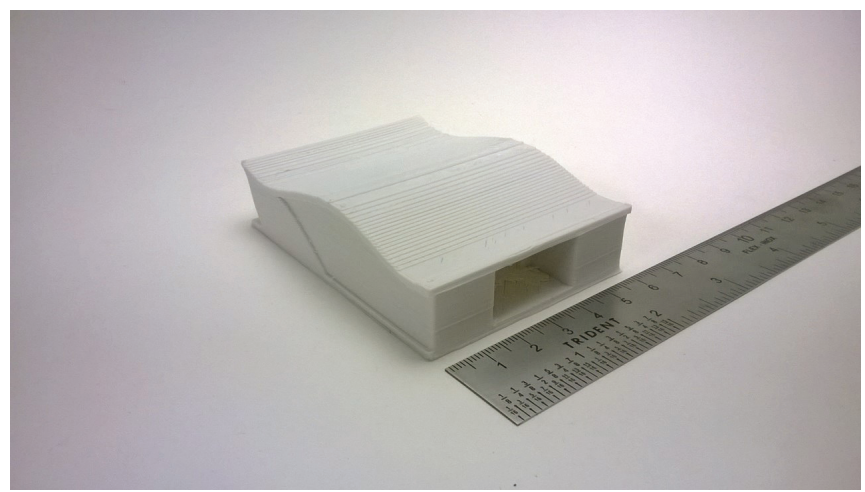

Figura 4: Modelo 01: Maquete de aluno do segundo semestre de

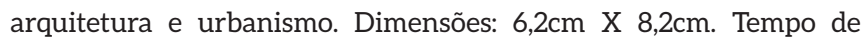
imprssão: 3 horas e 23 minutos.

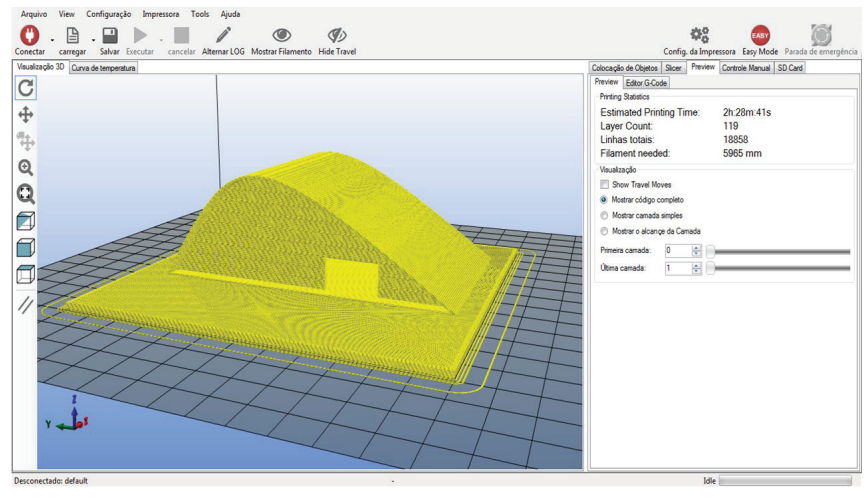

Figura 5: Modelo 02: Maquete de aluno do segundo semestre de arquitetura e urbanismo. Programa Repertier-host. 
O modelo 03, com sua forma não euclidiana desafia a representação bidimensional convencional e torna difícil a execução manual de um modelo físico. $O$ modelo levou 2 horas 55 minutos para ser impresso. Para esse tipo de projeto a utilização de uma impressora tridimensional se mostrou muito útil. Com o uso de programas de modelagem e a utilização de uma impressora tridimensional de baixo custo foi possível num espaço equivalente de tempo, em comparação com os outros dois modelos, propor uma forma complexa e não linear para um mesmo tema arquitetônico.

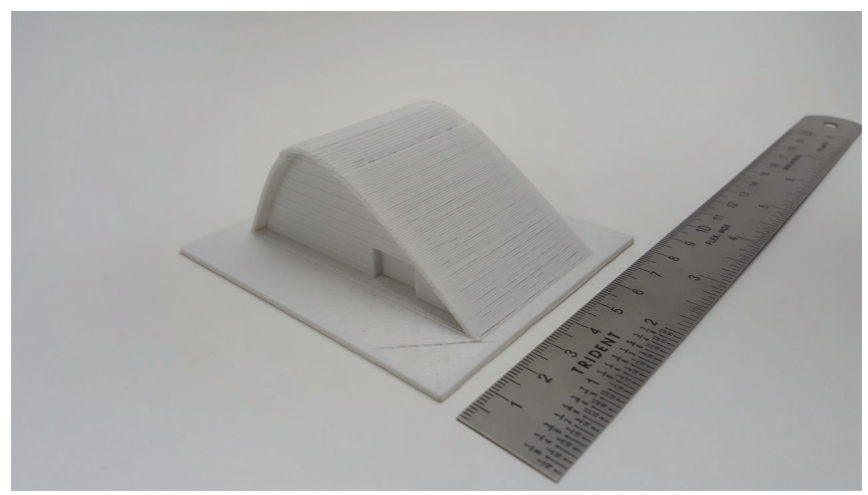

Figura 6: Modelo 02: Maquete de aluno do segundo semestre de arquitetura e urbanismo. Dimensões da base: $8,2 \mathrm{~cm} \mathrm{X} \mathrm{9,5cm.} \mathrm{Tempo}$ de impressão: 2 horas e 28 minutos.

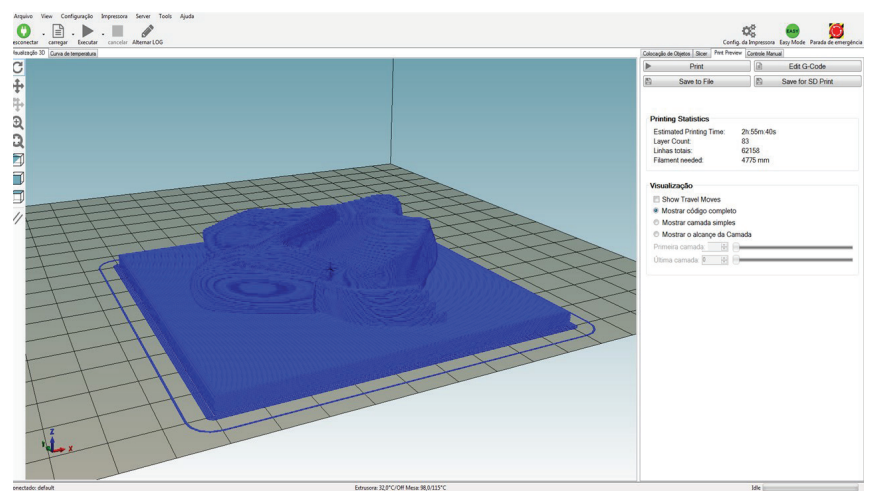

Figura 7: Modelo 03: Maquete de aluno do segundo semestre de arquitetura e urbanismo. Programa Repertier-host.

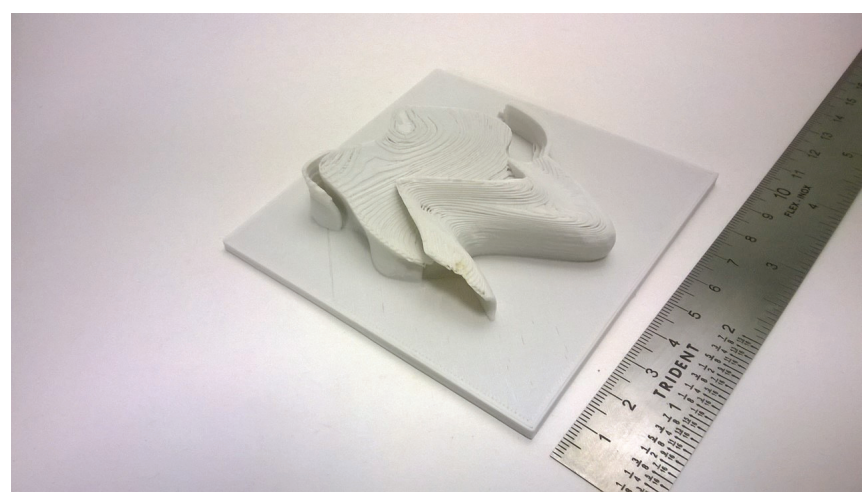

Figura 8: Modelo 03: Maquete de aluno do segundo semestre de arquitetura e urbanismo. Dimensões da base: $10 \mathrm{~cm} \mathrm{X} \mathrm{10cm.} \mathrm{Tempo} \mathrm{de}$ impressão: 2 horas e 55 minutos.

\section{Discussão}

Na produçãodostrês modelosobservamosqueotempode impressão é aproximado, não importando a complexidade do projeto. Os dois primeiros poderiam ter sido confeccionados de forma convencional. Com o modelo 03 observamos que a utilização de modeladores tridimensionais foi vital para a produção do projeto devido à sua complexidade. $\mathrm{O}$ projeto 03 seria prejudicado com a falta de um modelo físico para complementar o seu estudo e observação. Podemos concluir, com a produção do projeto e maquete do modelo 03 que o estudante pode criar sem amarras evitando assim a autocensura.

As impressoras tridimensionais poderão influenciar o ensino de arquitetura não apenas por permitir que modelos mais complexos possam sair da tela do computador para a mão dos alunos e professores. A impressão tridimensional também ajudará na compreensão de novos métodos de construção. As máquinas tipo desktop utilizam métodos análogos de impressão de máquinas maiores capazes de imprimir casas inteiras ou mesmo peças complexas para a indústria da construção civil. A presença das impressoras tridimensionais não determina as linguagens projetuais, mas podem evidenciar aos alunos a possibilidade de irem além de uma linguagem repetitiva e predominantemente ortogonal.

\section{Referências}

Kalisperis, L. N. (1996). CAD in Education: Penn State University, in ACADIA Quarterly, Volume 15, número 3.

Mitchell, W. J. (2001). Roll Over Euclid: How Frank Gehry Designs and Builds, in J. Fiona Ragheb (editor), Frank Gehry, Architect. New York: Guggenheim Museum Publications, p. 352-363.

Rocha, P. M. (1996). Maquetes de Papel, Cosac Naify, São Paulo. 